\title{
The Development Research of Computer-aided Rhythmic Gymnastics Selection System
}

\author{
Dong Chen ${ }^{1, a}$, Yang Yang ${ }^{2, b}$, Xiao Liu Li,c $^{3,2}$ \\ ${ }^{1,2}$ Hebei Chemical\&Pharmaceutical College \\ ${ }^{3}$ Hengshui University \\ a419876845@qq.com, b35949162@qq.com, c49255734@qq.com
}

\begin{abstract}
Keywords: Gymnastics, Scientific selection, Evaluation system, Junior principal component analysis, Fuzzy mathematics, Multi-level fuzzy integrated evaluation
\end{abstract}

\begin{abstract}
In the domain of current sports, the application of computer technology has already come up to certain depth and extent. But the research in the rhythmic gymnastics project has just started. Because the achievement of rhythmic gymnastics project depends on the various factors, it is the result for the comprehensive effect of plural factors. At present, our country rhythmic gymnastics faces the severe test both in the selection of suitable materials and in the editing and rehearsing of the complete sets of movement. So if the rhythmic gymnastics of our country want to keep and develop the existing athletics sports advantage in the world and break a zero record in medal in 2008 Olympic Games, we should strengthen the research efforts of sports science, accelerate the omni-directional development of our country rhythmic gymnastics relying on scientific and technological.

To the problems having existed in the rhythmic gymnastics project of our country, the text adopts the approaches of documents and materials, video analysis, statistics analysis. And study comprehensively and utilize the fictitious people's technology of the computer to develop the system of selecting suitable materials and editing composing for rhythmic gymnastics, carry on new exploration on the method of combining rhythmic gymnastics with computer.

Studies have indicated that the developing and research of system, that computer assists rhythmic gymnastics to select suitable materials, break through traditional experience, offer the peculiar mode and method of scientifically selecting materials for a Chinese rhythmic gymnast. This mode is not merely confined to the external shape and special body constitution index, it is more important that it is a scientific selection with comprehensive capability. Only need to get athletes' every shape index, we can obtain athletes' three-dimensional dummy, can also carry on the long-range appraising of selecting suitable materials through computer. And simplify the first time and intermediate procedure of selecting suitable materials, save the cost of selecting suitable materials, improve the success rate of selecting suitable materials, and establish the foundation that we edit and rehearse a series of athlete's movements. And the research and development of a series of athlete's movements system offer computer-aid technology in choosing movements, editing alignment figure, apparatus exchanging, integrative movement designing respect for the coach. That system makes the editing and rehearsing process of the collective project of rhythmic gymnastics to be visual and can be edited. And also can expand the thought of editing and coach's space and shorten cycle of editing and rehearsing, improve the quality of editing and rehearsing movements.
\end{abstract}

\section{Introduction}

In the modern competitive sports, the performance is the result of multiple factors comprehensive effect. The athlete scientific and effective selection of the material is the foundation stone of success. Practice has proved that the athletes material is a system engineering and pre-intermediate materials is the foundation. It is the main factor of the performance. If we select material limited to visual method and experience, it can not meet the requirement of modern athletic sports development and it's lack of scientificity or lack of foresight supported by the scientificity. Artistic gymnastics athlete selection material is based on outstanding artistic gymnastics athlete athletics ability structure 
model. Using observation, measurement and evaluation method forecasts those selected athletes' sporting potential in the future. Therefore, we need to review previous evaluation system for rhythmic gymnastics selection and make full use of the diversified functions of modern computer selection material. We should optimize the existing selection system, reduce the subjective error of the selection material and make full use of the theory of rhythmic gymnastics and practice knowledge to make predictions on the development of athletes. Develop the expert rhythmic gymnastics athletes selecting system in order to improve the reliability and success rate of our country's selection of rhythmic gymnastics. This research will be based on the present situation of our artistic gymnastics athlete selection materials, mainly establish and implement the diversity system of artistic gymnastics athlete selection materials from body shape and physical quality two aspects. At the same time, using computer application technology analyze the data and develop artistic gymnastics athlete scientific selection evaluation system in our country with the target of visualization, network. It provides standardized operating system software for pre-intermediate materials. At the same time, the research achievements have certain popularization significance to other related sports material selection.

\section{The Research Object}

The national youth artistic gymnastics athlete in 2003; International first - and second-line player; Part of the provincial level children artistic gymnastics athlete in 2005.

\section{The Theory Basis of Computer Aided Art Gymnastics}

The Advantage of Computer Aided Art Gymnastics. a)The computer provides us infinite data storage capacity. It can input physiological, psychological, biochemical indicators and analysis method on the book into the computer. b) Computer can calculate the accurate results relying on its powerful computing capacity. It greatly reduce the computational cost , shorten the calculation time, save manpower and material resources. c)It can analyze data and find the characteristics of athletes. It can fully understand and excavate the talent ability of athletes, predict its future trend of fitness and sports specialty trend. d) Computer can involve in $3 \mathrm{~d}$ virtual human technology. Simulate the complex event with virtual people through some calculation method. e) The computer has a great deal of flexibility. The select material system interface of rhythmic gymnastics is shown in figure 1.

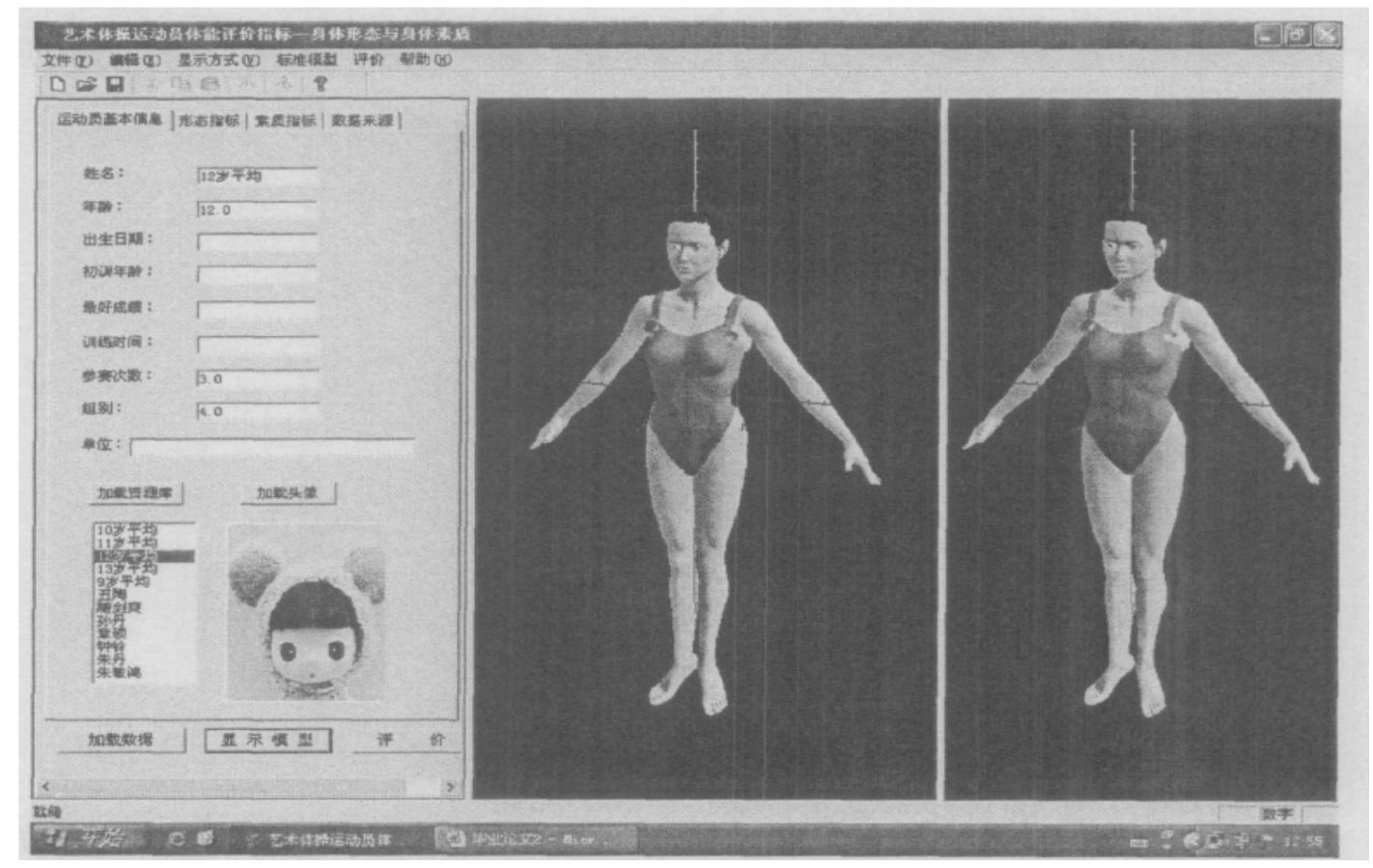

Figure 1: The select material system interface of rhythmic gymnastics 


\section{The Research Methods}

The Literature Material. Consult a large number of artistic gymnastics athlete selection and related documents through the way such as the Internet, library and so on.

Questionnaire Survey. Survey the relevant experts and scholars engaged in artistic gymnastics training and scientific research for many years in the aspect of rhythmic gymnastics athletes physical qualities such as flexibility, coordination, power, speed, bounce and so on. And then validity test it. The questionnaire's validity test adopts resurvey method. The time interval is two weeks and the correlation coefficient is 0.87 .

Interview Method. It mainly interviews our country artistic gymnastics international referees and coach and design the questionnaire for preliminary identification of the first and the second layer indicator.

Mathematical Statistics. (a)Principal component analysis method. Classify and allocate artistic gymnastics athlete body shape and physical quality indicators through factor analysis and cluster analysis in the principal component analysis.(b) Delphi method. Authenticate rhythmic gymnastics athletes physical quality measurement index through the Delphi method.

Fuzzy Mathematics Method. Test outstanding artistic gymnastics athlete index identification through fuzzy mathematics method.

Multi-level Fuzzy Comprehensive Evaluation Method. Evaluate artistic gymnastics athlete body shape and physical quality comprehensively through this method.

\section{The Results and Analysis}

Artistic Gymnastics Athletes Selection Material Research Status. Artistic gymnastics fully shows the elegant, strong and handsome qualities. It is a modern female athletics sports with beauty and artistic characteristics. With the rapid development of competitive rhythmic gymnastics technology and the constant change of the rules, we put forward higher requirements for artistic gymnastics athlete selection material. For a good artistic gymnastics athletes, a good body shape, quality condition and the psychological factor is necessary conditions to win in the international competition. It is also the material basis to complete a set of actions and create the excellent result. Therefore, artistic gymnastics athlete not only have beautiful body shape, exquisite technology, excellent artistic expression, but also have good competitive ability and good psychological quality. At present, the artistic gymnastics athlete selection mainly relies on the past experience of expert judgment and the fuzzy evaluation. The index system is not perfect and reasonable. In the process of evaluation, the subjective component is too big, so it is hard to avoid a larger deviation. Rhythmic gymnastics selection of body form and physical quality evaluation index and standard don't adapt to the new rules of rhythmic gymnastics in the development of the technology. According to the experience of the abroad, artistic gymnastics and intermediate materials should be reasonably predictive evaluation. And from the angle of the development, we need a variety of data for tracking analysis of the athletes. To this end, we need to review the existing evaluation system of our country's artistic gymnastics and intermediate materials. From the athletes body shape and physical quality, establish and implement the diversity of artistic gymnastics and intermediate material system. Make full use of the collective knowledge of experts to forecast the development of the athletes. Use the diversified functions of the modern computer to establish the mathematical model of multi-level fuzzy comprehensive evaluation. In order to reduce the subjective error of athletes selection material. Improve the success rate of our country artistic gymnastics athlete selection material.

Artistic Gymnastics Pre-intermediate Athletes Body Shape Evaluation System. Artistic gymnastics athlete body shape index identification is based on the 26 indicators commonly used in the anthropometry. Questionnaire survey statistics results show that $90 \%$ of experts think 9 morphological indexes have a great influence on artistic gymnastics in the 26 commonly used indexes. They are Height, length of upper limb and lower limb, leg length, Achilles tendon length, chest circumference, shoulder width, pelvis width and weight. And artistic gymnastics athlete's 
body is slender, the torso is short and limbs are long, this is one of the important features in the artistic quality of the project. Therefore, this paper is based on the principal component analysis. The initial body shape index of artistic gymnastics athlete is divided into length, circumference, width, PiYi thickness and weight five types of indicators. We choose height, weight, chest circumference, upper limb length, lower limb length, shoulder breadth, pelvis width and length of calves and Achilles tendon as the typical indicators of the project athletes body shape evaluation. However, the body form absolute index can't evaluate athlete's body shape comprehensively. It should generates a series of relative index derived from the height. Such as weight/height (\%), upper limb length/height (\%), lower limb length/height (\%), and pelvic width/height (\%), and (body weight and chest circumference)/height (\%), shoulder width - pelvis width (cm), Achilles tendon length/leg length (\%). Calculate the weight allocation of each relatively typical indicators and evaluate body shape comprehensively according to the allocation index weight. We can get her body shape comprehensive evaluation results from a 11-year-old athlete. The morphological evaluation is shown Table 1 . The physical quality evaluation is shown in Table 2.

Table 1: The morphological evaluation

\begin{tabular}{|c|c|c|c|c|}
\hline $\begin{array}{c}\text { Morphological } \\
\text { evaluation }\end{array}$ & The actual value & The average & $\begin{array}{c}\text { The reference } \\
\text { standard }\end{array}$ & Score \\
\hline Height (cm) & 156.50 & 149.91 & 5.23 & 88.00 \\
\hline $\begin{array}{c}\text { Weight/ } \\
\text { Height(\%) }\end{array}$ & 21.73 & 20.56 & 1.73 & 97.98 \\
\hline $\begin{array}{c}\text { ( Weight +The } \\
\text { chest ) / Height } \\
\text { (\%) }\end{array}$ & 68.37 & 64.08 & 3.33 & 92.62 \\
\hline $\begin{array}{c}\text { length of upper } \\
\text { limb/ Height(\%) }\end{array}$ & 42.17 & 42.17 & 2.71 & 78.23 \\
\hline $\begin{array}{c}\text { length of lower } \\
\text { limb/ Height(\%) }\end{array}$ & 59.42 & 57.17 & 1.27 & 97.20 \\
\hline $\begin{array}{c}\text { Pelvic } \\
\text { width/height (\%) }\end{array}$ & 14.06 & 15.06 & 1.92 & 92.42 \\
\hline $\begin{array}{c}\text { shoulder width - } \\
\text { pelvis width } \\
\text { (cm) }\end{array}$ & 13.00 & 117.20 & 189.81 & 59.90 \\
\hline $\begin{array}{c}\text { Achilles tendon } \\
\text { length/leg length } \\
\text { (\%) }\end{array}$ & 63.86 & The figure is good and the body is slightly fat , the proportion is good, \\
the average is 84.43
\end{tabular}

Table 2: The physical quality evaluation

\begin{tabular}{|c|c|c|c|c|}
\hline $\begin{array}{c}\text { Physical quality } \\
\text { evaluation }\end{array}$ & $\begin{array}{c}\text { The actual } \\
\text { value }\end{array}$ & The average & $\begin{array}{c}\text { The reference } \\
\text { standard }\end{array}$ & Score \\
\hline double roll jump & 121.00 & 73.0 & 22.6 & 88.08 \\
\hline $\begin{array}{c}\text { single roll jump } \\
\text { combination }\end{array}$ & 23.00 & 19.0 & 5.4 & 72.94 \\
\hline $\begin{array}{c}\text { quick kick on your } \\
\text { back }\end{array}$ & 46.00 & 46.4 & 5.8 & 67.66 \\
\hline body bends & 10.00 & 14.4 & 4.1 & 59.73 \\
\hline prone pull legs & 220.00 & 194.8 & 16.9 & 83.47 \\
\hline v control & 4.00 & 4.6 & 0.7 & 61.71 \\
\hline $\begin{array}{c}\text { The evaluation } \\
\text { results }\end{array}$ & \multicolumn{2}{|c|}{73.33} \\
\hline
\end{tabular}


Physical quality refers to the body ability shown by the artistic gymnastics athlete in the project's strength, speed, endurance and flexibility. According to the characteristics of artistic gymnastics, athletes must have the flexibility, coordination, speed, power, control, jumping ability etc. good physical condition. In this article, questionnaire and Delphi method is used to determine the artistic gymnastics athlete body quality measurement indexes. They are prone body bends, prone pull legs, single roll jump combination, quick kick on your back, v control, double roll jump. Classify and calculate weight distribution to all the measurements indexes through the principal component analysis method. The principal component to explain physical quality is shown in Table 3.

Table 3: The principal component to explain physical quality

\begin{tabular}{|c|c|}
\hline The main ingredients & Measurement \\
\hline Flexibility & body bends, prone pull legs \\
\hline The body control & v control \\
\hline Bounce and coordination & $\begin{array}{c}\text { double roll jump, single roll jump } \\
\text { combination, quick kick on your back }\end{array}$ \\
\hline
\end{tabular}

Artistic Gymnastics Athlete Comprehensive Evaluation System Model. According to the multi-level index system, this article uses the fuzzy multi-level comprehensive evaluation method, establish rhythmic gymnast multi-level fuzzy comprehensive evaluation model diagram.

Artistic Gymnastics Athlete Model Test. According to the result of principal component analysis, we obtain three main components about artistic gymnastics athletes' physical qualities: bounce and principal component coordination $\mathrm{Cl}$ (double roll jump, single roll jump combination, quick kick on your back), the body flexibility principal componentC2(prone body bends, prone pull legs), and physical control principal component C3(v control). At the same time, we can also get weight vector which is $\mathrm{Cl}, \mathrm{C} 2$ and $\mathrm{C} 3$ to ultimate objective physical $\mathrm{D}$ and the measurements to each principal component. $A=[0.5206,0.28,0.1994]$. The weight vector about double roll jump, single roll jump combination, quick kick on your back to $\mathrm{C} 1$ is $\mathrm{A} 1=[0.7008,0.2082,0.091]$. The weight vector about prone body bends, prone pull legs to $\mathrm{C} 2$ is $\mathrm{A} 2=[0.8414,0.1586]$. C3 contains only $\mathrm{V}$ control measurement.A3=1. All levels fuzzy evaluation matrix obtained through coaches and referees expert testimony. Finally it concludes the athlete's physical quality evaluation results. We can also get the results of the athletes' form in the same way. Then it concludes the athletes' body shape and physical quality evaluation results and model.

\section{Conclusion}

Comprehensively evaluate artistic gymnastics athlete selection material body form and physical quality evaluation index through computer software. It can reduce subjective error when select material of rhythmic gymnastics and improve the success rate of select material. It provides feasible operation basis from theory and practice for our country artistic gymnastics athlete selection material.

\section{References}

[1] Egle Abruzzini.CODE OF POINTS RHYTHMIC GYM-NASTICS. 2001.

[2] Wang Ailan. The study of the artistic gymnastics training [M].Beijing; Peoples Sports Publishing House,1993.(In Chinese) 